\title{
Neuroelectric blocking factors in human and animal sera evaluated using the isolated frog spinal cord
}

\author{
C. L. S C H A U F, F.A. DA V IS, D. A. SA CK, \\ B. J . RE E D, A N D R. L. KES L E R \\ From the Departments of Neurological Sciences and Physiology, \\ Rush Medical College, Chicago, Illinois 60612, USA
}

SYNOPS IS The effects of sera from guinea-pigs with experimental allergic encephalomyelitis (EAE) and multiple sclerosis (MS) patients were evaluated and compared with the activity of control sera using the isolated frog spinal cord. Ventral root responses (VRR) were recorded during supramaximal ipsilateral dorsal root stimulation in the presence and absence of $25 \%$ serum. In control experiments with normal human and guinea-pig sera we observed a consistent, reversible increase in VRR averaging $20 \%$ and $17 \%$ respectively, and in no case was any significant decrease produced. In contrast, sera from EAE guinea-pigs 12 to 19 days after injection produced an equally rapid, reversible decrease in VRR. The decrease averaged $36 \%$ and was highly significant $(P<0.0001)$ relative to controls. Similarly, sera from MS patientsD on the average decreased the VRR by $26 \%$, and this again was significant compared witho controls $\left(\mathrm{P}<10^{-6}\right)$.

The literature regarding the presence of neuroelectric blocking agents in the sera of patients with multiple sclerosis (MS) and animals with cxperimental allergic encephalomyelitis (EAE) and the relationship, if any, between the presence of such agents and the disease process itself has in recent years become increasingly complex and controversial. Some 10 years ago Bornstein and Crain (1965) reported that sera from rabbits with experimental allergic encephalomyelitis and MS patients during acute exacerbations reversibly blocked the electrical activity of cultured mouse cerebral cortex cells. Shortly thereafter Cerf and Carels (1966) reported that the application of MS sera to the isolated frog spinal cord produced a reversible inhibition of the polysynaptic ventral root response (VRR) to ipsilateral dorsal root or lateral column stimulation. In both preparations heating the sera to $56^{\circ} \mathrm{C}$ for 30 minutes was reported to abolish the neurotoxic effect, which could, however, be reconstituted by the

(Accepted 8 March 1976.) addition of a fresh source of complement. Par ticularly in the Cerf and Carels (1966) studies, numerous control sera were examined without any neurotoxic effect being found. In fact, normal sera werc reported to enhance the ventral root response above that recorded in normal oxygenated Ringer solution.

In contrast with these results, Seil et al. $(1975,1976)$ reported in extensive studies that the neuroelectric blocking factor(s) claimed by Bornstein and Crain (1965) to exist specifically in EAE and MS sera were also present to a comparable extent in a variety of control sera. Using mouse cerebral neocortex cultures, they found no significant difference between the blocking activity of sera from MS patients and normal subjects, or between the sera of rats injected with guinea-pig white matter in Freund's complete adjuvant (FCA) and those injected with various control antigens, including FCA alone. Additionally, they failed to confirm the thermal lability of this factor reported by Bornstein and Crain (1965). Seil et al. (1976) concluded that such a neurotoxic 
effect is a 'nonspecific property of many human and animal sera not specifically related to the pathogenesis of demyelinating diseases'.

It is not difficult to reconcile these studies with those of Bornstein and Crain (1965), since in the latter case few controls were examined. However, recently, an independent report by Lumsden et al. (1975) has appeared which tends to confirm the original Bornstein and Crain (1965) conclusions. In this case control and EAE sera were applied to cultures of neonatal rat cerebellum. Not only were a large number of control sera examined with negative results, but the blocking activity of EAE sera was shown to depend on the maturity of the tissue culture cells as well as on the time after immunization at which serum specimens were obtained.

The basis for these discrepancies is not clear. Perhaps the differences between one tissue culture system and another are sufficient to explain the varying responses. In any case it has clearly become essential to attempt to repeat the earlier Cerf and Carels (1966) studies, for MS as well as for animals with EAE.

\section{METHODS}

Specimens of Rana temporaria with a body length of about $15 \mathrm{~cm}$ (5-6 in) were purchased from the Mogul Ed/Lemburger Co., Oshkosh, Wisconsin. After immobilization by chilling, the animal's spinal cord, along with $2-3 \mathrm{~cm}$ lengths of the dorsal and ventral roots, was dissected free beginning at the cervical enlargement by standard techniques (Tebecis and Phillis, 1969). The cord was rapidly hemisected and placed on a waxcovered channel in the floor of a lucite chamber. The spinal roots ran laterally through holes in two partitions separating the central channel from side pools filled with mineral oil. A two channel constant perfusion pump was used to recirculate Ringer's solution $(115 \mathrm{mmol} / 1 \mathrm{NaCl} ; 2.5 \mathrm{mmol} / 1$ $\mathrm{KCl} ; 1.8 \mathrm{mmol} / 1 \mathrm{CaCl}_{3} ; 2.0 \mathrm{mmol} / 1$ Tris; $0.5 \mathrm{~g} / 1$ glucose) from a reservoir constantly perfused with a mixture of $95 \% \mathrm{O}$. and $5 \% \mathrm{CO}_{\text {. }}$. Solutions were changed simply by switching to a different reservoir and discarding the first $20 \mathrm{ml}$ removed from the chamber. Chamber volume was $2 \mathrm{ml}$. External $\mathrm{pH}$ was adjusted to 7.3 at the standard experimental temperatures of $15-20^{\circ} \mathrm{C}$.

Pairs of platinized platinum stimulating and recording electrodes were placed under corres- ponding dorsal and ventral roots, the most distal recording electrodes being located under a crushed segment of ventral root. A sintered $\mathrm{Ag}$ / $\mathrm{AgCl} / \mathrm{Pt}$ hybrid electrode (Annex Electrodes) was used to earth (ground) the chamber. Ventral root responses to supramaximal dorsal root volleys were recorded via a Tektronix FM 122 preamplifier and 5440 storage oscilloscope. Photographs were taken and the peak amplitude of the VRR determined, as well as the total area of the VRR, using a planimeter. Generally, the peak amplitudes were used to determine the effect of serum samples.

Usually, the VRR in normal Ringer's solution was observed to increase for the first hour after dissection due to initial spinal shock. We routinely recorded responses every 15 minutes until the preparation stabilized then began to apply test sera diluted with a solution whose salt composition had been adjusted to keep all cation concentrations unchanged from those of the normal Ringer solution at a serum concentration of $25 \%$. After application of each test serum, responses were monitored at five minute intervals until the response stabilized or for a minimum of $15 \mathrm{~min}$ utes. Then the preparation was returned to normal Ringer solution to allow for recovery.

\section{RESULTS}

Figure 1 shows the ventral root responses obtained in Ringer solution and during the application of $25 \%$ normal human sera. Not only is the amplitude of the VRR seen to be relatively consistent in Ringer solution, but there is a clear potentiation of the response during application of normal human serum. Table 1 summarizes experiments using serum obtained from 14 normal human subjects. The amplitude of the ventral root response (VRR) was measured before (B), during (D), and after (A) exposure to $25 \%$ normal sera, and the relative effect calculated as the ratio of the response in the presence of serum to the average of the amplitudes obtained in Ringer solution before and after serum application. In all cases we allowed 15 minutes for equilibration after solution changes. The data have been normalized to the amplitude of the VRR obtained before application of serum. The average of the responses obtained during the recovery period relative to the initial values was $1.03 \pm$ 0.16 , indicating that, although the VRR might 

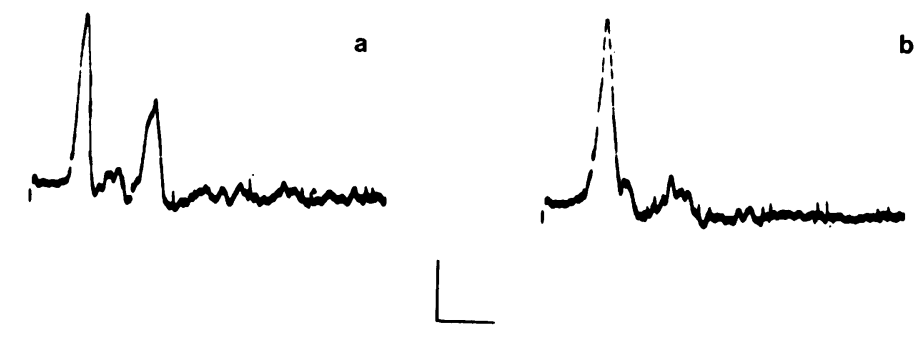

C

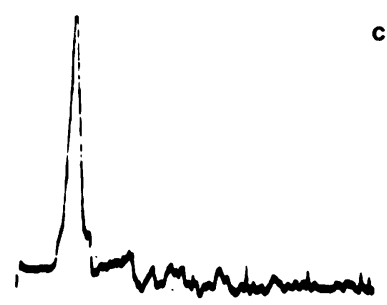

b d
FIG. 1 Ventral root responses recorded from an isolated frog spinal cord at $15^{\circ} \mathrm{C}$ in (a) Ringer's solution, (b) Ringer's solution 20 minutes later, (c) $25 \%$ normal human serum diluted with modified Ringer's solution to maintain total electrolyte concentrations constant

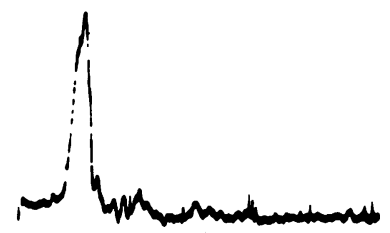
-10 minutes after application, (d) Ringer's solution 10 minutes after removal of the normal human serum. Vertical and horizontal scales are $20 \mu \mathrm{V}$ and $5 \mathrm{~ms}$ respectively.
T A B L E 1

EFFECTS OF NORMAL HUMAN SERA ON ISOLATED FROG SPINAL CORD

\begin{tabular}{|c|c|c|c|c|}
\hline \multirow[t]{2}{*}{ Subject $^{1}$} & \multicolumn{3}{|c|}{$V R R$ amplitude (VRR) } & \multirow{2}{*}{$\begin{array}{c}\text { Relative } \\
\text { effect }^{3}\end{array}$} \\
\hline & $B^{\mathbf{3}}$ & $D$ & $A$ & \\
\hline TH & 1.0 & 1.49 & 1.32 & 1.28 \\
\hline TH* & 1.0 & 1.35 & 0.98 & 1.36 \\
\hline $\mathrm{CS}$ & 1.0 & 1.0 & 0.92 & 1.04 \\
\hline CS* & 1.0 & 1.10 & 1.04 & 1.08 \\
\hline TP & 1.0 & 0.96 & 0.80 & 1.07 \\
\hline TP* & 1.0 & 1.13 & 1.0 & 1.13 \\
\hline DS & 1.0 & 1.5 & 1.1 & 1.43 \\
\hline DS* & 1.0 & 1.30 & 1.03 & 1.28 \\
\hline $\mathbf{R S}$ & 1.0 & 1.14 & 1.05 & 1.11 \\
\hline RS* & 1.0 & 1.07 & 1.0 & 1.07 \\
\hline DF & 1.0 & 1.22 & 1.16 & 1.13 \\
\hline $\mathbf{D F}^{*}$ & 1.0 & 1.02 & 0.93 & 1.06 \\
\hline BH* & 1.0 & 1.21 & 1.23 & 1.08 \\
\hline CP & 1.0 & 1.28 & 1.02 & 1.27 \\
\hline BR & 1.0 & 1.23 & 0.81 & 1.36 \\
\hline DS & 1.0 & 1.40 & 0.90 & 1.47 \\
\hline $\mathrm{CC}^{*}$ & 1.0 & 1.42 & 1.40 & 1.18 \\
\hline $\mathrm{JC}^{*}$ & 1.0 & 1.29 & 0.93 & 1.34 \\
\hline $\mathrm{CG}^{*}$ & 1.0 & 1.42 & 1.26 & 1.26 \\
\hline MP & 1.0 & 1.26 & 0.82 & 1.39 \\
\hline DP & 1.0 & 1.11 & 1.0 & 1.11 \\
\hline GG & 1.0 & 0.95 & 0.98 & 0.96 \\
\hline Averages & & $1.22 \pm 0.17$ & $1.03 \pm 0.16$ & $1.20 \pm 0.15$ \\
\hline
\end{tabular}

$1 *$ Indicates serum frozen at $-20^{\circ} \mathrm{C}$ for $24-72$ hours.

${ }^{2}$ Data normalized to VRR amplitude obtained before (B) application of serum.

${ }^{3}$ Relative effect $=2 D /(A+B)$, where $B, D$, and $A$ are the amplitudes of the VRR obtained before, during, and after application of $25 \%$ serum and $B=1.0$. show some slight progressive change with time in any particular preparation, there was no consistent tendency for the VRR to eitheg deteriorate or improve.

Serum specimens obtained for our initial sis control subjects were evaluated both fresh (within two hours) or after storing for 24-72 hours at $-20^{\circ} \mathrm{C}$. The average ratio of the relative effect obtained with frozen sera to that obtained with fresh sera was $1.00 \pm 0.06$. Thus there was no apparent effect of the freeze/ thaw cycle on the ability of normal serum to potentiate the VRR. Subsequent studies were therefore done without regard to time of collection of control sera. Note that in these instances the effects of a particular serum were evaluated on different preparations, demonstrating the consistency of the effect of a particular serum from one frog spinal cord to another (Table 1).

The average potentiation produced by normal human serum was to $1.22 \pm 0.17$ times the control response in Ringer's solution with the results ranging from essentially no effect $(-4 \%)$ to a $47 \%$ increase in VRR. In no case was the VRR significantly decreased by normal serum, in contrast with the results obtained on cultured CNS tissue (Seil et al., 1975, 1976). 
Our data on the potentiation by control sera agree fairly well with that of Cerf and Carels (1966) who obtained an average $42 \%$ increase (range $9 \%$ to $84 \%$ ) in VRR in 12 preparations. This is particularly significant in that these authors removed the preparation from the recording chamber for exposure to different media, whereas we simply changed the perfusate with the preparation remaining in place.

In addition to normal human sera, we also studied the response of the isolated frog spinal cord to the application of serum obtained by intracardiac puncture from normal male guinea pigs (400-500 g). Here again normal serum potentiates the VRR with an average increase to $1.17 \pm 0.16$ times control. There is no significant difference compared with human serum, and again in the VRR was never significantly decreased by normal serum.

In contrast with these results, Fig. 2 illustrates the effect of applying fresh serum from a patient with multiple sclerosis to the isolated spinal cord. The amplitude of the VRR was rapidly and reversibly decreased by $25 \%$ serum and could not be increased by further increasing the amplitude of the originally supramaximal stimulus to the dorsal root. The results of a study of $25 \mathrm{MS}$ patient sera are given in Table 2 and Fig. 3.
T A B L E 2

EFFECTS OF MS SERA ON THE ISOLATED

FROG SPINAL CORD

\begin{tabular}{|c|c|c|c|c|c|}
\hline \multirow{2}{*}{$\begin{array}{l}\text { Code } \\
\text { number }\end{array}$} & \multirow{2}{*}{$\begin{array}{l}\text { Clinical } \dagger \\
\text { status }\end{array}$} & \multicolumn{3}{|c|}{$V R R$ amplitude* } & \multirow{2}{*}{$\begin{array}{l}\text { Relative } \\
\text { effect }\end{array}$} \\
\hline & & $B$ & $D$ & $A$ & \\
\hline 1 & $\mathrm{E}$ & 1.0 & 0.72 & 0.71 & 0.85 \\
\hline 2 & E & 1.0 & 0.56 & 0.73 & 0.65 \\
\hline 3 & S & 1.0 & 0.85 & 0.90 & 0.90 \\
\hline 4 & $\mathrm{E}$ & 1.0 & 0.33 & 0.87 & 0.35 \\
\hline 5 & $\bar{E}$ & 1.0 & 0.45 & 1.0 & 0.45 \\
\hline 6 & $\mathbf{S}$ & 1.0 & 1.0 & 1.0 & 1.0 \\
\hline 7 & $\mathbf{S}$ & 1.0 & 0.64 & 1.07 & 0.62 \\
\hline 8 & $S$ & 1.0 & 1.06 & 0.88 & 1.13 \\
\hline 9 & $\mathrm{E}$ & 1.0 & 0.38 & 1.02 & 0.37 \\
\hline 10 & $\mathbf{S}$ & 1.0 & 1.25 & 1.20 & 1.14 \\
\hline 11 & $\mathbf{S}$ & 1.0 & 1.01 & 1.0 & 1.01 \\
\hline 12 & $\mathbf{E}$ & 1.0 & 0.64 & 1.02 & 0.63 \\
\hline 13 & E & 1.0 & 0.55 & 1.0 & 0.55 \\
\hline 14 & $\mathbf{S}$ & 1.0 & 0.57 & 1.0 & 0.57 \\
\hline 15 & $\mathbf{S}$ & 1.0 & 0.50 & 1.16 & 0.45 \\
\hline 16 & $\mathbf{E}$ & 1.0 & 0.83 & 1.0 & 0.83 \\
\hline 17 & $\mathbf{S}$ & 1.0 & 0.73 & 0.79 & 0.81 \\
\hline 18 & $\mathbf{S}$ & 1.0 & 1.12 & 1.21 & 1.02 \\
\hline 19 & S & 1.0 & 0.92 & 1.04 & 0.90 \\
\hline 20 & $\mathbf{S}$ & 1.0 & 0.84 & 0.93 & 0.90 \\
\hline 21 & $\mathbf{S}$ & 1.0 & 0.89 & 0.89 & 0.94 \\
\hline 22 & $\mathbf{S}$ & 1.0 & 0.73 & 0.96 & 0.74 \\
\hline 23 & $\mathbf{S}$ & 1.0 & 0.30 & 1.05 & 0.28 \\
\hline \multicolumn{3}{|l|}{ Averages } & $0.73 \pm 0.26$ & $0.98 \pm 0.13$ & $0.74 \pm 0.26$ \\
\hline
\end{tabular}

*Same conventions as in Table 1.

$\dagger \mathrm{E}=$ exacerbating; $\mathrm{S}=$ stable.
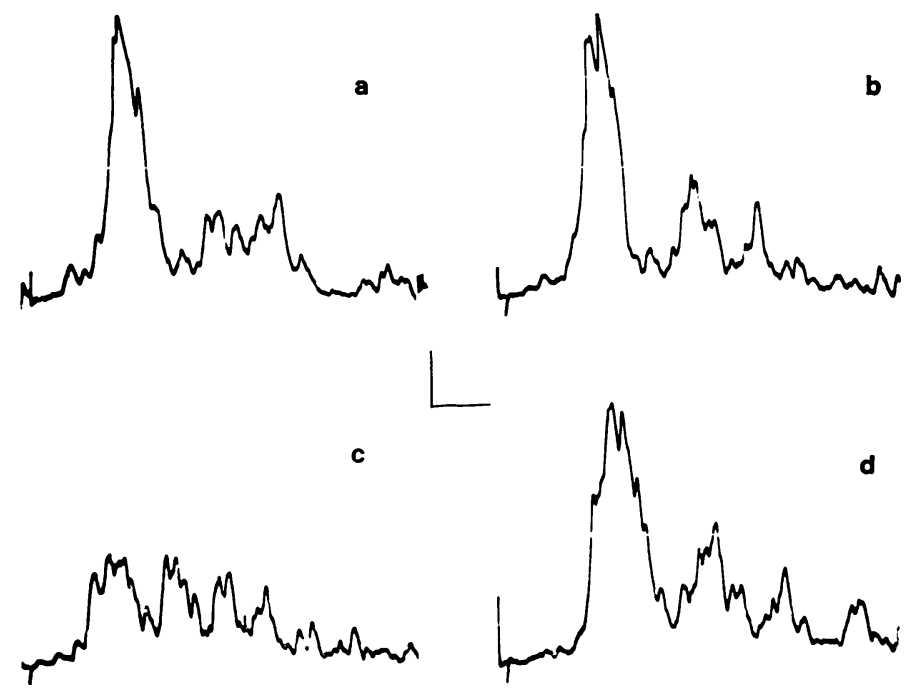

FIG. 2 Ventral root responses recorded from an isolated frog spinal cord at $17^{\circ} \mathrm{C}$ in (a) Ringer's solution, (b) Ringer's solution 20 minutes later, (c) $25 \%$ serum from patient with multiple sclerosis, and (d) Ringer's solution after a 10 minute recovery. Vertical and horizontal scales are $10 \mu \mathrm{V}$ and $2 \mathrm{~ms}$ respectively. 


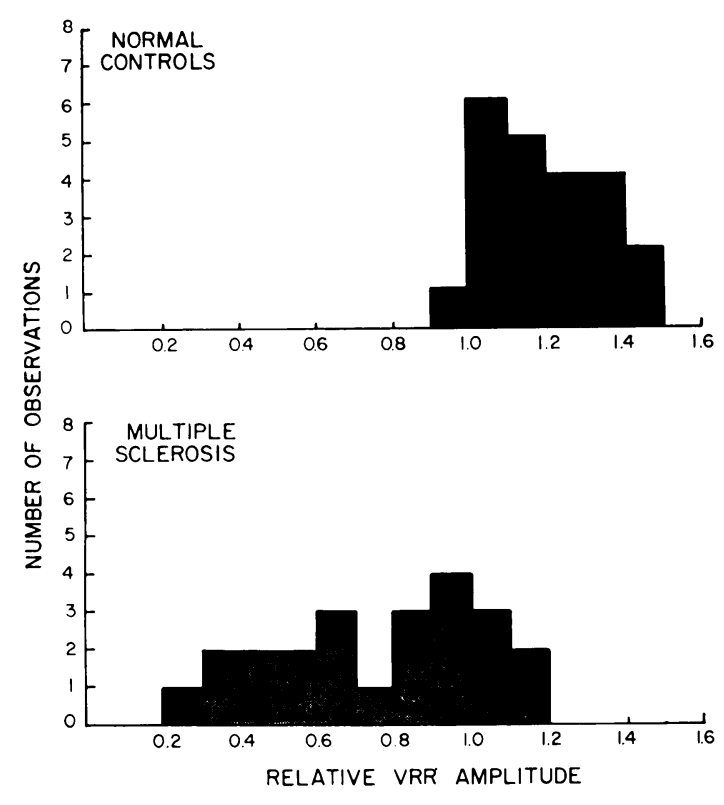

FIG. 3 Relative VRR amplitudes after application of $25 \%$ normal human sera (top) or $25 \%$ serum from randomly selected MS patients (bottom). The relative VRR amplitude was calculated by dividing the VRR amplitude during exposure to serum by the average of the VRR amplitudes in Ringer's solution before and after exposure to serum.

Again, the VRR response was measured before, during, and after application of sera, and the relative effect calculated as in Table 1 . The average VRR obtained during the recovery period was $0.98 \pm 0.13$ times the initial control response, demonstrating the essentially complete reversibility of the effect as well as the stability of the preparation. During application of fresh MS sera the average VRR amplitude was reduced to $0.73 \pm 0.26$ times the control value (range 0.25 to 1.14 ) and compared with normal human sera the difference in the means is statistically significant $\left(\mathrm{P}<10^{-6}\right.$, unpaired $t$ test). Figure 3 and Table 2 suggest, however, that the MS sera may segregate bimodally, with some patients producing little or no decrease in the VRR while others strongly inhibit.

Table 2 also gives the clinical status of each patient (exacerbating or stable) as evaluated by a neurologist before we tested the neuroelectric activity of the patient's sera. Detailed inspection of the blocking effect yields a slight correlation with the clinical evaluation. The patients classed as exacerbating depressed the VRR to $0.59 \pm 0.19$ times the control value, while those classed as stable depressed the VRR to $0.83 \pm 0.25$. These differences are marginally significant $(\mathrm{P}<0.03)$.

In our final series of experiments serum specimens were obtained from randomly bred male guinea-pigs at various times after injection with rabbit spinal cord in FCA. These results are summarized in Table 3 . The average decrease in VRR produced by EAE sera taken from animals 12-19 days after inoculation was to $0.64 \pm 0.19$ times control, a difference highly significant compared with normal sera $(\mathrm{P}<0.0001)$. Animals whose sera were examined more than 20 days after inoculation did not usually produce an effect significantly different from that produced by the uninjecteds controls $(0.99 \pm 0.11)$.

A limited number of experiments was carried out using sera from patients with cerebral strokes to test whether CNS damage by itself, is capable of causing the appearances of neuroelectric blocking activity. In none of the four cases examined was there any significant decrease in VRR, the average amplitude

TA B LE 3

EFFECTS OF EAE SERA ON THE ISOLATED FROG SPINAL CORD

\begin{tabular}{rccccc}
\hline \multirow{2}{*}{$\begin{array}{l}\text { Exp't. } \\
\text { No. } \begin{array}{c}\text { Days post } \\
\text { innoculation }\end{array}\end{array}$} & \multicolumn{3}{c}{ VRR amplitude } & $\begin{array}{c}\text { Relative } \\
\text { effect }\end{array}$ \\
\cline { 3 - 5 } & & $B$ & $D$ & $A$ & \\
\hline 1 & 19 & 1.0 & 0.50 & 1.10 & 0.48 \\
2 & 20 & 1.0 & 1.16 & 1.0 & 1.16 \\
3 & 21 & 1.0 & 1.03 & 1.08 & 0.99 \\
4 & 13 & 1.0 & 0.60 & 1.18 & 0.55 \\
5 & 15 & 1.0 & 0.30 & 0.50 & 0.40 \\
6 & 20 & 1.0 & 1.0 & 1.0 & 1.0 \\
7 & 12 & 1.0 & 0.70 & 0.68 & 0.83 \\
8 & 12 & 1.0 & 0.90 & 1.33 & 0.77 \\
9 & 16 & 1.0 & 0.82 & 1.0 & 0.82 \\
10 & 16 & 1.0 & 0.76 & 1.36 & 0.64 \\
11 & 21 & 1.0 & 1.02 & 1.04 & 1.0 \\
12 & 16 & 1.0 & 0.86 & 1.0 & 0.86 \\
13 & 16 & 1.0 & 0.29 & 0.76 & 0.33 \\
14 & 16 & 1.0 & 0.86 & 1.06 & 0.75 \\
15 & 20 & 1.0 & 1.11 & 1.32 & 0.96 \\
16 & 20 & 1.0 & 0.90 & 1.20 & 0.82 \\
\hline
\end{tabular}

Same conventions as in Table 1. 
being $1.05 \pm 0.05$ times normal, not significantly different from values obtained with normal human sera.

\section{DISCUSSION}

This study demonstrates the existence of neuroelectric blocking activity in sera from MS patients and from EAE guinea-pigs 12 to 19 days after immunization, and shows that this activity is specific to these conditions, at least insofar as we are unable to detect any comparable phenomena using normal human or guinea-pig sera, or sera from patients with CNS damage secondary to cerebrovascular disease.

The data obtained from MS patients and from randomly bred guinea-pigs tend to segregate bimodally. Some sera block very effectively, while others block only slightly or not at all, or perhaps slightly potentiate. The average effect of the latter group is still significantly different from the effects of normal control sera, however, suggesting the possibility that the blocking activity is even greater than recorded because of a masking effect by potentiating factor(s). Whether this is, in fact, the case will require either a more quantitative assay, or identification and elimination of the potentiating effect of normal serum.

It is not apparent from the data presented here whether there is a very direct connection between the activity of neuroelectric blocking factor(s) and the clinical status of the MS patient. We have tested a single patient during acute exacerbation and after a seven day course of ACTH therapy associated with marked clinical improvement. Before hospitalization the patient's sera decreased the VRR by $38 \%$, and after ACTH treatment it was ineffective (VRR increased by $1 \%$ ). In another case a patient with a chronically progressive course was tested at a six week interval during which there was no apparent change in her condition. The earlier sera decreased the VRR by $65 \%$, while the second specimen decreased the VRR by only $10 \%$. Clearly much more extensive longitudinal studies of selected MS patients are required before any definitive statements can be made, and moreover may require the development of a more sensitive assay of neuroelectric blocking activity and/or at least a partial characterization of the factor(s) responsible for such activity.

The specificity of blocking activity for EAE and MS sera confirms the earlier work of Cerf and Carels (1966) who also noted a similar potentiating effect of normal sera. It is in marked contrast with recent tissue culture studies (Seil et al., 1975) in which blocking activity was equally abundant in a variety of control sera. A possible explanation of these studies is that the electrical activity found in tissue culture systems is relatively more labile and sensitive to a component of normal serum which the frog spinal cord is either insensitive to, or which is masked by the VRR potentiating effect characteristic of normal serum.

The mechanism of this potentiating effect of normal serum remains obscure. It could be due to the quite high concentration $\left(10^{-4} \mathrm{~mol} / \mathrm{l}\right)$ of putative excitatory transmitters such as glutamate found in normal serum but additional experiments are required to settle this point.

Supported by the Morris Mutiple Sclerosis Research Fund, by a grant from the Kroc Foundation, and by NIH Research Career Development Award I KO4 NS 00004-01 to C.L.S.

\section{REFERENCES}

Bornstein, M. D., and Crain, S. M. (1965). Functional studies of cultured brain tissues as related to demyelinative disorders, Science, 148, 1242-1244.

Cerf, J. A., and Carels, G. (1966). Multiple sclerosis: serum factor producing reversible alteration in bicelectric responses, Science, 152, 1066-1068.

Lumsden, C. E., Howard, L., Aparisio, S. R., and Bradbury, M. (1975). Antisynaptic antibody in allergic encephalomyelitis. 2 . The synapse blocking effects in tissue culture of demyelinating sera from experimental allergic encephalomyelitis, Brain $R e$ search, 93, 283, 299.

Seil, F. J., Leiman, A. L., and Kelly, J. M. (1976). Neuroelectric blocking factors in multiple sclerosis and normal human sera, Archives of Neurology (Chic.), 33, 418-422.

Seil, F. J., Smith, M. E., Leiman, A. L., and Kelly, J. M. (1975). Myelination inhibiting and neurcelectric blocking factors in experimental allergic encephalomyelitis. Science, 187, 951-953.

Tebecis, A. K., and Phillis, J. W. (1969). Pharmacology of the isolated toad spinal cord. In Experiments in Physiology and Biochemistry, vol 2. Edited by G. A. Kerkut. Academic Press: New York. 